\title{
The $P_{2}$ ' residue is a key determinant of mesotrypsin specificity: Engineering a high affinity inhibitor with anticancer activity
}

\author{
Moh'd A. Salameh", Alexei S. Soares ${ }^{\dagger}$, Alexandra Hockla", Derek C. Radisky ${ }^{*}$, and Evette S. \\ Radisky ${ }^{*}, 1$ \\ "Department of Cancer Biology, Mayo Clinic Cancer Center, Jacksonville, Florida 32224, USA \\ †Biology Department, Brookhaven National Laboratory, Upton, New York 11973, USA
}

\section{SYNOPSIS}

PRSS3/mesotrypsin is an atypical isoform of trypsin, the upregulation of which has been implicated in promoting tumor progression. Mesotrypsin inhibitors could potentially provide valuable research tools and novel therapeutics, but small molecule trypsin inhibitors have low affinity and little selectivity, while protein trypsin inhibitors bind poorly and are rapidly degraded by mesotrypsin. Here, we use mutagenesis of a mesotrypsin substrate, the Kunitz domain of the amyloid precursor protein (APPI), and of a poor mesotrypsin inhibitor, bovine pancreatic trypsin inhibitor (BPTI), to dissect mesotrypsin specificity at the key $\mathrm{P}_{2}{ }^{\prime}$ position. We find that bulky and charged residues strongly disfavor binding, while acidic residues facilitate catalysis. Crystal structures of mesotrypsin complexes with BPTI variants provide structural insights into mesotrypsin specificity and inhibition. Through optimization of the $\mathrm{P}_{1}$ and $\mathrm{P}_{2}^{\prime}$ residues of BPTI, we generate a stable, high affinity mesotrypsin inhibitor with an equilibrium binding constant $K_{i}$ of $5.9 \mathrm{nM}$, a $>2000$-fold improvement in affinity over native BPTI. Using this engineered inhibitor, we demonstrate the efficacy of pharmacologic inhibition of mesotrypsin in assays of breast cancer cell malignant growth and pancreatic cancer cell invasion. While further improvements in inhibitor selectivity will be important before clinical potential can be realized, our studies support the feasibility of engineering protein protease inhibitors of mesotrypsin and highlight their therapeutic potential.

\section{Keywords}

endopeptidase; protease inhibitor; enzyme inhibition; crystal structure; protein engineering; drug discovery

\section{INTRODUCTION}

Proteases that are aberrantly expressed in the tumor microenvironment represent key contributors to tumor growth and progression [2], as well as a potentially promising category of drug targets $[3,4]$. However, a major challenge in the development of therapeutic protease inhibitors has been the identification of sufficiently selective inhibitors, since individual oncogenic proteases typically belong to large families of closely structurally related enzymes, such as the matrix metalloproteinases or the trypsin-like serine proteases [4]. Insufficiently selective drugs are associated with toxicity caused by interference with

${ }^{1}$ Corresponding author: Evette S. Radisky, 310 Griffin Building, 4500 San Pablo Road, Jacksonville, FL 32224, USA; radisky.evette@mayo.edu.

Protein Data Bank accession numbers: The atomic coordinates and structure factors (PDB codes 3P92 and 3P95) have been deposited in the Protein Data Bank, Research Collaboratory for Structural Bioinformatics, Rutgers University, New Brunswick, NJ. 
diverse physiological processes, and may lack efficacy as a result of simultaneously targeting pro- and antitumorigenic proteases [5].

Recently, evidence has begun to accumulate suggesting that the trypsin isoform PRSS3/ mesotrypsin promotes cancer growth, invasion, and progression. Mesotrypsin, encoded by the PRSS3 gene, is produced and secreted as a digestive zymogen by the pancreas [6]; a splice isoform with an alternative exon 1, lacking a classical secretion signal, is expressed in the brain [7, 8]. PRSS3 expression has also been reported in a variety of tumors and cancer cell lines, and has been associated with cancer progression [9-11]. PRSS3/mesotrypsin expression is associated with metastasis and poor survival in non-small cell lung cancer (NSCLC) patients [9] and in pancreatic cancer patients [11]. Mesotrypsin enhanced transendothelial migration of NSCLC cells, suggesting a functional role in metastasis [9], and mesotrypsin promoted pancreatic cancer cell proliferation and invasion in culture models and tumor progression and metastasis in animal models [11]. We have found PRSS3 expression to be upregulated with advancing malignancy in a culture model of breast cancer progression, where it contributes to malignant growth [10]. Thus, mesotrypsin represents a potential target for cancer therapy, if potent and selective inhibitors can be developed; this effort depends upon defining aspects of binding specificity which differ between mesotrypsin and other trypsin-like serine proteases.

Although mesotrypsin shows high sequence homology with the major digestive trypsins, we and others have found that unique sequence and structural features, most notably Arg-193 (in most other serine proteases a highly conserved Gly), contribute to distinct specificity and functional properties [12-18]. Structural studies reveal that Arg-193 contributes to a positively charged electrostatic surface potential in the vicinity of the $S_{2}{ }^{\prime}$ subsite [13], and must undergo substantial conformational rearrangements to permit binding of substrates or inhibitors with bulky $\mathrm{P}_{2}^{\prime}$ residues $[16,18]$. Consequences include minimal or markedly reduced activity toward specific protein substrates of other trypsins [14], unusual resistance to many polypeptide trypsin inhibitors $[12,13,19]$, the ability to degrade some trypsin inhibitors as substrates $[14,17,18]$, and unusual substrate specificity for small polar residues at the $\mathrm{P}_{1}{ }^{\prime}$ position [15] and for polypeptide substrates constrained in a canonical conformation [17]. Importantly, the unique structural features of the mesotrypsin active site may also offer the opportunity to develop tailored inhibitors that can target mesotrypsin selectively, for use as probes to study the role of mesotrypsin in cancer models, and perhaps ultimately as cancer therapeutics.

Here, we use mutagenesis of a model mesotrypsin substrate to define the unusual $\mathrm{P}_{2}{ }^{\prime}$ substrate specificity of mesotrypsin. We demonstrate the relevance of optimizing interactions at this site by engineering the poor mesotrypsin inhibitor bovine pancreatic trypsin inhibitor (BPTI) [16] into a high affinity mesotrypsin inhibitor, and gain structural insights into mesotrypsin substrate specificity and inhibition by solving high resolution crystal structures of mesotrypsin-inhibitor complexes. We further show that our optimized mesotrypsin inhibitor functions in pharmacologic inhibition of mesotrypsin in physiologically relevant assays of breast cancer cell malignant growth and pancreatic cancer cell invasion.

\section{EXPERIMENTAL}

\section{Production of recombinant proteins}

Recombinant human mesotrypsinogen, human cationic trypsinogen, and human anionic trypsinogen, as well as a catalytically inactive S195A mutant of mesotrypsinogen, were expressed in E. coli, isolated from inclusion bodies, refolded, purified, and activated with bovine enteropeptidase as previously described [16, 20, 21]. Kunitz domain inhibitors were 
expressed in the methylotrophic yeast Pichia pastoris under control of the alcohol oxidase $(A O X 1)$ promoter using the expression vector pPICZaA (Invitrogen); constructs, expression and purification of APPI-WT, BPTI-WT, and several mutant inhibitors has been described previously [17, 18, 22, 23]. Additional mutations were introduced using the QuikChange kit (Stratagene), and sequence verification and expression screening were conducted as previously described [18].

\section{Inhibition studies}

Mesotrypsin, cationic trypsin, and anionic trypsin concentrations were quantified by activesite titration using 4-nitrophenyl 4-guanidinobenzoate (Sigma), and APPI and BPTI variant concentrations were determined by titration with bovine trypsin (Sigma), as previously described [16]. Concentrations of the chromogenic substrate benzyloxycarbonyl-Gly-ProArg-p-nitroanalide (Z-GPR-pNA) (Sigma) were determined by end point assay. For determination of mesotrypsin inhibition constants, enzyme assays performed at $37{ }^{\circ} \mathrm{C}$ in the presence of varying concentrations of substrate and inhibitor were followed spectroscopically for 3-5 min, and initial rates were determined from the absorbance increase caused by the release of $p$-nitroaniline $\left(\varepsilon_{410}=8480 \mathrm{M}^{-1} \mathrm{~cm}^{-1}\right)$, as previously described [16]. Data were globally fitted by multiple regression to the classic competitive inhibition equation (equation 1), using Prism (GraphPad Software, San Diego CA). Reported inhibition constants are average values obtained from multiple independent experiments.

$$
v=\frac{k_{\mathrm{cat}}[\mathrm{E}]_{0}[\mathrm{~S}]}{K_{\mathrm{m}}\left(1+[\mathrm{I}] / K_{\mathrm{i}}\right)+[\mathrm{S}]}
$$

For measurement of inhibition constants with cationic and anionic trypsins, the observation of slow, tight-binding behavior required an alternative kinetic treatment, using methods that we have described previously [16]. Reactions were run at $25^{\circ} \mathrm{C}$, and were followed spectroscopically for $16 \mathrm{~h}$ so that reliable steady-state rates could be obtained. Inhibition constants were calculated using equation 2 as previously described [16], where $v i$ and $v 0$ are the steady-state rates in the presence and absence of inhibitor, $K_{\mathrm{M}}$ is the Michaelis constant for substrate cleavage, and $\left[\mathrm{S}_{0}\right]$ and $\left[\mathrm{I}_{0}\right]$ are the initial concentrations of substrate and inhibitor. Calculations were performed using $K_{\mathrm{M}}$ values of $36.5 \mu \mathrm{M}$ for cationic trypsin and $22.6 \mu \mathrm{M}$ for anionic trypsin, determined from Michaelis-Menten kinetic studies.

$$
\left(v_{0}-v_{\mathrm{i}}\right) / v_{\mathrm{i}}=\left[\mathrm{I}_{0}\right] / K_{\mathrm{i}}\left(1+\left[\mathrm{S}_{0}\right] / K_{\mathrm{M}}\right)
$$

\section{Impact of $P_{2}$ ' residues on free energies of association, catalysis, and transition state stabilization}

Using the absence of a $\mathrm{P}_{2}{ }^{\prime}$ sidechain in APPI-M17G as the baseline for comparison of all other variants, and using $1 / K_{i}$ as an approximation of $K_{a}$, the equilibrium association constant, we calculated the change in free energy of association $\Delta \Delta G_{\mathrm{a}}{ }^{\circ}(\mathrm{Gly} 17 \mathrm{X})$ from equation 3. Changes in the free energy of catalysis $\Delta \Delta G_{\text {cat }}(\mathrm{Gly} 17 \mathrm{X})$ and in the transitionstate stabilization energy $\Delta \Delta G_{\mathrm{T}}^{\ddagger}(\mathrm{Gly} 17 \mathrm{X})$ were similarly calculated from equations 4 and 5 , respectively.

$$
\Delta \Delta G_{a}^{\circ}=-R T \ln \frac{\left(K_{\mathrm{a}}\right)_{\mathrm{APPI}-\mathrm{X} 17}}{\left(K_{\mathrm{a}}\right)_{\mathrm{APPI}-\mathrm{Gl} 17}}
$$




$$
\begin{gathered}
\Delta \Delta G_{\text {cat }}=-R T \ln \frac{\left(k_{\text {cat }}\right)_{\mathrm{APPI}-\mathrm{X} 17}}{\left(k_{\mathrm{cat}}\right)_{\mathrm{APPI}-\mathrm{Gly} 17}} \\
\Delta \Delta G_{\mathrm{T}}{ }^{*}=-R T \ln \frac{\left(k_{\mathrm{cat}} / K_{\mathrm{m}}\right)_{\mathrm{APPI}-\mathrm{X} 17}}{\left(k_{\mathrm{cat}} / K_{\mathrm{m}}\right)_{\mathrm{APPI}-\mathrm{Gly} 17}}
\end{gathered}
$$

\section{Inhibitor hydrolysis studies}

The depletion of intact APPI and BPTI variants in time course incubations with active mesotrypsin was monitored by SDS-PAGE and HPLC as previously described [16-18]; SDS-PAGE was used to obtain initial qualitative estimates reaction rates, while HPLC was used to quantitatively determine catalysis rates $\left(k_{\text {cat }}\right)$. Incubations of mesotrypsin with BPTI mutants were carried out in $0.1 \mathrm{M}$ Tris- $\mathrm{HCl} \mathrm{pH} 8.0$ and $1 \mathrm{mM} \mathrm{CaCl}_{2}$ at $37^{\circ} \mathrm{C}$; BPTI variant concentration was $50 \mu \mathrm{M}$ and mesotrypsin concentration was 1-5 $\mu \mathrm{M}$. Aliquots for HPLC analysis were withdrawn from BPTI hydrolysis reactions at periodic intervals, adjusted to 6 $\mathrm{M}$ urea and $2 \mathrm{mM} \mathrm{DTT}$, incubated for $10 \mathrm{~min}$ at $37^{\circ} \mathrm{C}$, quenched by acidification to $\mathrm{pH} 1$ and then frozen at $-20^{\circ} \mathrm{C}$ until analyzed as previously reported [16]. Incubations of mesotrypsin with APPI mutants were carried out similarly, except that APPI concentration was $50 \mu \mathrm{M}$ and mesotrypsin concentrationwas in the range of 10-500 nM. APPI hydrolysis time point samples were not denatured or reduced; instead samples were quenched immediately by acidification to $\mathrm{pH} \leq 1$ and then frozen at $-20^{\circ} \mathrm{C}$ until analyzed as previously described $[17,18]$. Enzyme, Kunitz inhibitors, and hydrolysis products were resolved by HPLC and the disappearance of intact Kunitz inhibitors over time was quantified by peak integration as described previously [16-18]; initial rates were obtained by linear regression using a minimum of 5 data points within the initial linear phase of the reaction, and not exceeding $50 \%$ conversion of intact inhibitor to hydrolysis products. Hydrolysis rates reported for each inhibitor represent the average of 2-3 independent experiments.

\section{Crystalization of mesotrypsin-BPTI-K15R/R17G and mesotrypsin.BPTI-K15R/R17D variant complexes}

The catalytically inactive mesotrypsin-S195A mutant was mixed with BPTI-K15R/R17G or BPTI-K15R/R17D in a 1:1 stoichiometric molar ratio. The heterodimeric complexes were further purified by HiLoad Superdex 75 gel filtration chromatography (GE Healthcare), exchanged into $10 \mathrm{mM}$ Na acetate, $\mathrm{pH} 6.5$, and concentrated to $\sim 3 \mathrm{mg} / \mathrm{mL}$. Complexes were crystallized at $22{ }^{\circ} \mathrm{C}$ in hanging drops, over a reservoir of $25 \%$ PEG4000, $0.2 \mathrm{M} \mathrm{Na}$ acetate and $100 \mathrm{mM}$ Tris, $\mathrm{pH} 8.0$; drops $(4 \mu \mathrm{L})$ were prepared by mixing equal volumes of protein and reservoir solutions. Crystals $(0.2 \times 0.4 \times 0.1 \mathrm{~mm})$ appeared within 2 days and grew over the course of 6 days. Crystals were harvested, soaked in a cryoprotectant solution (30\% PEG4000, $0.2 \mathrm{M} \mathrm{Na}$ acetate, $100 \mathrm{mM}$ Tris pH 8.0 and 15\% glycerol) and flash-frozen in liquid $\mathrm{N}_{2}$.

\section{X-ray data collection, structure solution and model refinement}

Synchrotron X-ray data were collected from crystals at $100 \mathrm{~K}$ using ADSC CCD detectors at beam lines X12-B, X12-C, and X25 at the National Synchrotron Light Source, Brookhaven National Laboratory. The software package HKL2000 [24] was used for integrating, scaling and merging the reflection data. The structures were solved by molecular replacement using the program Phaser [25] operated by PHENIX [26], using the mesotrypsin.BPTI-WT complex structure (PDB ID 2R9P) [16] as the search model. The successful solution 
contained one copy of the heterodimeric complex in the asymmetric unit. Cycles of manual rebuilding in COOT [27] were alternated with automated refinement using the refinement module of the PHENIX software suite [28]. A test set comprised of $10 \%$ of the total reflections was excluded from refinement to allow calculation of the free $R$ factor. Waters, ions, and alternative conformations of protein residues were added using COOT [27]. At early stages, TLS refinement was employed, with each protein chain assigned to a separate TLS group. At later stages of refinement, full anisotropic treatment of atomic displacement parameters was employed, and hydrogen atoms were added in the riding positions. All superpositions and structure figures were created using the graphics software Pymol (http://pymol.sourceforge.net).

\section{Breast cancer cell 3D malignant growth asays}

HMT-3522 T4-2 human mammary epithelial cells were cultured as previously described [10]. 3D cultures in Matrigel were established using the "on-top" protocol [29], in which different concentrations of BPTI-wt or BPTI-K15R/R17G inhibitors were added to the upper layer of Matrigel and to the culture medium replaced every 2 days, as previously described [10]. After 7 days in culture, cells were photographed and assessed for colony size.

\section{Pancreatic cancer cell invasion assays}

Capan-1 human pancreatic cancer cells (gift of Dr. P. Storz, Mayo Clinic) were cultured in DMEM supplemented with $10 \%$ fetal bovine serum. Cells were transduced with lentiviral short hairpin RNA construct NM_002771.2-454s1c1 targeting human PRSS3, from the MISSION TRC-Hs1.0 library (Sigma), or with a negative control vector containing a short hairpin that does not recognize any human genes, as previously described [10]. After selection with $1 \mu \mathrm{g} / \mathrm{mL}$ puromycin, pooled transductants were split into three parallel cultures for (a) analysis of PRSS3 transcript levels by qRT/PCR as previously described [10], (b) analysis of mesotrypsin protein levels, and (c) assessment of cellular invasiveness. Knockdown was assessed at the protein level in cell lysates by Western blotting using a custom rabbit polyclonal antiserum (Cocalico Biologicals, Reamstown, PA) raised against mesotrypsin peptide acetyl-TQAECKASYPGKITNS-NH 2 conjugated to KLH (EZ Biolab, Carmel, IN). For transwell invasion assays, cells were suspended in DMEM + 0.1\% BSA, mixed with BPTI-K15R/R17G as noted, and $1 \times 10^{5}$ cells/well were used to seed 24-well 8.0 micron transwell inserts (BD Biosciences) coated with $50 \mu \mathrm{g}$ Matrigel (BD Biosciences). Cells were allowed to invade for $24 \mathrm{~h}$ at $37^{\circ} \mathrm{C}$ and $5 \% \mathrm{CO}_{2}$ toward a chemoattractant in the lower chamber comprised of NIH/3T3-conditioned serum-free medium containing $50 \mu \mathrm{g} / \mathrm{mL}$ ascorbic acid and $50 \mathrm{ng} / \mathrm{mL}$ SDF-1 $\beta$ (R\&D Systems) before methanol fixation, crystal violet staining, photographing of filters and counting of cells on the underside of the filter using Image Pro Plus 6.3 software (MediaCybernetics).

\section{RESULTS}

\section{The $P_{2}$ ' position plays a critical role in mesotrypsin substrate binding affinity}

Previous structural studies have found that the distinctive Arg-193 of mesotrypsin influences the steric contour and electrostatic potential of the substrate binding site, and interacts closely with the $\mathrm{P}_{2}{ }^{\prime}$ residue of a bound substrate or inhibitor molecule $[13,16,18]$. Thus, we hypothesized that the identity of the $\mathrm{P}_{2}^{\prime}$ residue might be a major determinant of mesotrypsin substrate specificity. To investigate this hypothesis, we selected the recombinant Kunitz domain of the amyloid precursor protein (APPI) as a model protein substrate, since we have recently shown that mesotrypsin rapidly and efficiently hydrolyzes a specific Arg-Ala peptide bond in APPI [17], and we employed site-directed mutagenesis to replace the native $\mathrm{P}_{2}{ }^{\prime}$ Met of APPI with a variety of alternative amino acid residues. 
We measured binding affinity in competitive inhibition experiments in which the APPI variants were studied as inhibitors of the hydrolysis by mesotrypsin of a competing substrate, the chromogenic tripeptide Z-GPR-pNA. All of the inhibition data were well described by the competitive model, as we have reported previously for the inhibition of mesotrypsin by APPI-WT [17]; values of the equilibrium inhibition constants $K_{i}$ for all APPI $\mathrm{P}_{2}^{\prime}$ variants are summarized in Table 1 . Because the competitive inhibition equation also describes the enzymatic reaction of one substrate in the presence of a competing substrate, with the condition that $K_{i}$ must be equivalent the Michaelis constant $K_{m}$ for the competing substrate [30], the $K_{i}$ values in Table 1 also represent $K_{m}$ values for cleavage of the APPI variants as mesotrypsin substrates.

We found that replacement of the bulky hydrophobic Met, which occupies the $\mathrm{P}_{2}{ }^{\prime}$ position of APPI-WT, with small (Gly, Ala), aromatic (Phe, Tyr), basic (Arg), or acidic (Asp, Glu) amino acids produced a spectrum of $K_{i}$ values spanning over two orders of magnitude, illustrating the importance of this position in mesotrypsin binding discrimination. The tightest binding of the APPI variants tested was APPI-M17G, which completely lacks a side chain at the $\mathrm{P}_{2}^{\prime}$ position and possesses a $K_{i}$ value toward mesotrypsin of $4.7 \mathrm{nM}$. We then considered APPI-M17G as a baseline for assessing the impact of the various other $\mathrm{P}_{2}{ }^{\prime}$ side chains on mesotrypsin association. Using $1 / K_{i}$ as an approximation of $K_{a}$, the equilibrium association constant, we calculated the change in free energy of association $\Delta \Delta G_{\mathrm{a}}^{\circ}$ (Gly17X); these $\Delta \Delta G_{\mathrm{a}}{ }^{\circ}$ values are listed in Table 1.

It is apparent that all $\mathrm{P}_{2}{ }^{\prime}$ side chains are deleterious for binding by comparison with Gly. When $\Delta \Delta G_{\mathrm{a}}{ }^{\circ}(\mathrm{Gly} 17 \mathrm{X})$ values are plotted $v s$. the number of non-hydrogen atoms in each side chain [31,32], there is a clear trend toward weaker binding (larger $\Delta \Delta G_{\mathrm{a}}^{\circ}$ ) with increasing steric bulk of the $\mathrm{P}_{2}{ }^{\prime}$ residue (Fig. $1 A$ ). Side chain charge appears to contribute to a deleterious effect on binding as well, since variants possessing acidic (Asp, Glu) or basic (Arg) side chains each display higher $\Delta \Delta G_{\mathrm{a}}{ }^{\circ}$ than those featuring uncharged residues of similar size.

\section{Acidic residues at the $\mathbf{P}_{\mathbf{2}}$ ' position accelerate mesotrypsin-catalyzed hydrolysis}

We next used HPLC assays to directly quantify cleavage of APPI variants by mesotrypsin in time course incubations $[17,18]$. Because hydrolysis studies used APPI concentrations $>50$ fold higher than $K_{m}$ values, mesotrypsin binding capacity was saturated and observed rates of hydrolysis approximate true catalytic rate constants ( $\left.k_{\text {cat }}\right)$. Values of $k_{\text {cat }}$ and specificity constant $k_{\text {cat }} / K_{m}$ for each APPI variant considered as a substrate for mesotrypsin are summarized in Table 2. We again used APPI-M17G as a baseline for comparison, and calculated changes in the free energy of catalysis $\Delta \Delta G_{\text {cat }}(\mathrm{Gly} 17 \mathrm{X})$ and in transition-state stabilization energy $\Delta \Delta G_{\mathrm{T}}^{\ddagger}(\mathrm{Gly} 17 \mathrm{X})$ reflecting contributions to catalysis of each non-Gly $\mathrm{P}_{2}{ }^{\prime}$ residue tested.

Mutations at the $\mathrm{P}_{2}{ }^{\prime}$ position generally appear to have very little impact on mesotrypsin catalytic rate constants, irrespective of residue size (Fig. $1 B$ ); the only exceptions noted were for replacement of the $\mathrm{P}_{2}{ }^{\prime}$ amino acid with acidic residues Asp or Glu, which both accelerated $k_{\text {cat }}$ by $\sim 30$-fold, contributing $\sim-2 \mathrm{kcal} / \mathrm{mol}$ to the free energy of catalysis. Since most $\mathrm{P}_{2}{ }^{\prime}$ residues had substantial impact on $K_{m}$ but negligible effect on $k_{\text {cat }}$, the impact on specificity constant $k_{\text {cat }} / K_{m}$ is dominated by $K_{m}$ effects, and a plot of $\Delta \Delta G_{\mathrm{T}}^{\ddagger}(\mathrm{Gly} 17 \mathrm{X})$ shows positive (deleterious) changes in transition-state stabilization energy trending upward with residue size (Fig. 1C). Asp and Glu diverge from this pattern; for these residues, the deleterious effect of the acidic side chain on binding is substantially offset by the favorable impact on catalytic rate. 


\section{Optimization of the $\mathrm{P}_{2}$ ' residue converts BPTI into a potent mesotrypsin inhibitor}

We have previously found that while APPI is a rapidly cleaved substrate of mesotrypsin [17], the structurally homologous trypsin inhibitor BPTI is a slowly hydrolyzed weak inhibitor of mesotrypsin $\left(K_{i}=14 \mu \mathrm{M}\right)[16,18]$. We hypothesized that $\mathrm{P}_{2}{ }^{\prime}$ mutations characterized in the context of APPI would have parallel effects on the binding affinity and vulnerability to mesotrypsin hydrolysis of BPTI, and that this information might be used to engineer BPTI as a more potent inhibitor of mesotrypsin. Starting with the BPTI-K15R variant, which possesses a $\mathrm{P}_{1}$ Arg residue and binds 6-fold more tightly to mesotrypsin than BPTI-WT [18], we introduced either Gly or Asp at the $\mathrm{P}_{2}{ }^{\prime}$ position. These new mutants, along with the previously reported BPTI-K15R and BPTI-K15R/R17M variants [18], allow us to compare the impact of an absent (Gly), hydrophobic (Met), basic (Arg), or acidic (Asp) side chain at the BPTI $\mathrm{P}_{2}{ }^{\prime}$ position. For each variant, $K_{i}$ was obtained from competitive inhibition experiments and $k_{\text {cat }}$ derived from HPLC-based hydrolysis studies as described previously $[16,18]$. Similarly to our studies above with APPI, we have used the BPTI variant with $\mathrm{P}_{2}{ }^{\prime}$ Gly as a baseline for comparison, allowing evaluation of the energetic contributions of Met, Arg, or Asp side chains to mesotrypsin binding and catalysis.

Comparing the $K_{i}$ values for mesotrypsin obtained with the BPTI variants (Table 3), it is apparent that as in the case of the substrate APPI, all tested non-Gly residues at the $\mathrm{P}_{2}{ }^{\prime}$ position proved deleterious for binding. The rank order of BPTI variants ranked according to $K_{i}$ matched that observed for the APPI variants: Gly showed tightest association, followed by Met, Asp, and then Arg, suggesting that for BPTI as for APPI, the bulk and charge of the $\mathrm{P}_{2}{ }^{\prime}$ residue were important determinants of binding specificity. Mutation of the $\mathrm{P}_{2}{ }^{\prime}$ residue to Gly in BPTI-K15R/R17G produced the tightest-binding inhibitor of mesotrypsin reported to date, with a $K_{i}$ value of $5.9 \mathrm{nM}$, over 2000 -fold lower than that of BPTI-WT, and over 400-fold lower than that of BPTI-K15R mutated only at the $\mathrm{P}_{1}$ position, another strong determinant of mesotrypsin binding specificity [18].

An effective polypeptide inhibitor must resist inactivation and degradation through proteolytic cleavage as well as compete effectively with substrates for binding to the active site of the protease. The $k_{\text {cat }}$ values for mesotrypsin cleavage of BPTI variants (Table 4) show that the identity of the $\mathrm{P}_{2}{ }^{\prime}$ residue has a significant impact on the proteolytic stability vs. vulnerability to mesotrypsin of BPTI. As in the $K_{i}$ comparisons, the rank orders of corresponding BPTI and APPI variants ranked according to $k_{\text {cat }}$ remain the same, with $\mathrm{P}_{2}{ }^{\prime}$ Gly the most resistant to proteolysis followed by Met, Arg, and then Asp, but for the BPTI variants the impact of $\mathrm{P}_{2}{ }^{\prime}$ substitutions on $k_{\text {cat }}$ is magnified. In particular, the $\mathrm{P}_{2}{ }^{\prime}$ Asp variant BPTI-K15R/R17D displays a 90-fold enhanced catalytic rate relative to the $\mathrm{P}_{2}{ }^{\prime}$ Gly variant. Notably, the $\mathrm{P}_{2}$ ' Gly variant is the best inhibitor both from the viewpoint of binding affinity and from the viewpoint of proteolytic stability to mesotrypsin. Table 4 also reports $k_{\text {cat }} / K_{m}$ substrate specificity constants for each BPTI variant considered as a substrate rather than an inhibitor of mesotrypsin; all of the BPTI variants feature specificity constants 2-3 orders of magnitude lower than those seen for the corresponding APPI variants in Table 2 as a consequence of their much slower rates of cleavage by mesotrypsin; this resistance to proteolysis is an attribute conferred by the BPTI scaffold [18].

\section{Optimized BPTI variant retains strong affinity toward other trypsins}

To assess the potential binding selectivity of BPTI-K15R/R17G toward mesotrypsin relative to other trypsins, we also measured inhibition constants $K_{i}$ for BPTI-WT and BPTIK15R/ R17G against recombinant human cationic trypsin and human anionic trypsin. Because the association of BPTI with these trypsins follows a slow, tight-binding model [16], it was necessary to use an alternative approach to the measurement of $K_{i}$ values as described in the Experimental section. As shown in Table 5, both inhibitors bind substantially more tightly to 
cationic and anionic trypsin than to mesotrypsin. However, while the dual mutations introduced in BPTI-K15R/R17G have improved $K_{i}$ toward mesotrypsin by a factor of 2277 , they have weakened binding toward cationic and anionic trypsin by a factor of 1.6-1.8. Thus while BPTI-WT shows strong selectivity toward both cationic and anionic trypsins in preference to mesotrypsin by a gap of nearly six orders of magnitude, for BPTI-K15R/R17G this gap has been narrowed to a factor of 180-200. BPTI-K15R/R17G appears to be a relatively nonselective inhibitor with an unusual capacity to potently inhibit mesotrypsin in addition to other trypsins.

\section{Structures of mesotrypsin in complex with BPTI $P_{2}$ 'variants reveal multiple conformations of Arg-193}

To determine why the $\mathrm{P}_{2}{ }^{\prime}$ residue plays such a critical role in inhibitor binding and hydrolysis by mesotrypsin, we crystallized and solved X-ray structures for the mesotrypsin.BPTI-K15R/R17G and mesotrypsin·BPTI-K15R/R17D complexes, and compared these to the previously published crystal structure of mesotrypsin bound to BPTIWT (PDB ID 2R9P) [16]. To avoid heterogeneity associated with BPTI proteolysis, we used an inactive mesotrypsin-S195A mutant. Diffraction data were measured to 1.6 and $1.3 \AA$ resolution for mesotrypsin.BPTI-K15R/R17G and mesotrypsin·BPTI-K15R/R17D complexes, respectively. Both crystals belong to the space group $\mathrm{P} 2{ }_{1}$ and exhibit very similar unit cell parameters, with a single heterodimer in the asymmetric unit. Both structures were solved by molecular replacement; Table 6 summarizes the crystal, data collection, and refinement statistics.

In comparing the structures of the BPTI-K15R/R17G, BPTI-K15R/R17D, and BPTI-WT complexes, we find that while each model features BPTI similarly bound in the canonical fashion at the mesotrypsin active site, the different $\mathrm{P}_{2}{ }^{\prime}$ residues show significant differences in interface topology (Fig. 2A,B,C). In the mesotrypsin.BPTI-K15R/R17G structure, Arg-193 protrudes downward, enveloping the BPTI Gly-17 backbone (Fig. $2 A$ ). In this conformation, Arg-193 has $96.4 \AA^{2}$ of accessible surface area (ASA), $65.5 \AA^{2}(68 \%)$ of which becomes buried by contact with BPTI-K15R/R17G (calculations from the PDBePISA server [33]). By contrast, in the mesotrypsin-BPTI-WT complex, the presence of the BPTI $\mathrm{P}_{2}{ }^{\prime}$ Arg residue displaces Arg-193 to a position buried between the two $\mu$-barrel domains of the enzyme; in this conformation, Arg-193 has only $48.9 \AA^{2}$ ASA, $30.2 \AA^{2}(62 \%)$ of which becomes buried by contact with BPTI (Fig. 2B). The mesotrypsin.BPTI-K15R/R17D complex is intermediate between these two extremes; Arg-193 adopts yet a third distinct conformation, with $62.3 \AA^{2}$ ASA, $30.8 \AA^{2}$ (49\%) of which becomes buried by contact with BPTI (Fig. 2C).

The discrete conformations of Arg-193 found in the mesotrypsin·BPTI-K15R/R17G structure and in the mesotrypsin.BPTI-WT structure are well-ordered, as evidenced by strong electron density for the entire side chain (Fig. 2D,E). The $\mathrm{P}_{2}^{\prime}$ Arg residue of BPTIWT is well ordered, as well (Fig. 2E). By contrast, the intermediate position adopted by Arg-193 in the mesotrypsin.BPTI-K15R/R17D structure, as well as the position of the $\mathrm{P}_{2}{ }^{\prime}$ Asp-17 residue of BPTI, appear to be somewhat less stable and less well ordered, as both Arg-193 and Asp-17 show weaker electron density despite the higher resolution of this 1.3 $\AA$ structure (Fig. $2 F$ ). While $\mathrm{N}_{\varepsilon}$ of Arg-193 and $\mathrm{O}_{\delta 2}$ of Asp-17 are separated by only $2.75 \AA$ in the model, the weak electron density of these side chains, and the presence of multiple weak water peaks as alternative $\mathrm{H}$-bonding partners to Asp-17 $\mathrm{O}_{\delta 2}$ (Fig. $2 F$ ), suggest that the interaction between these residues may be weak and transient in nature. This structural interpretation is consistent with our biochemical data, as we found that BPTI-K15R/R17D exhibited only marginally better mesotrypsin affinity than BPTI-K15R, which features positively charged Arg-17 at the $\mathrm{P}_{2}^{\prime}$ position (Table 3). Thus, the Arg-193 - Asp-17 electrostatic interaction appears to contribute minimally to binding affinity. 
Further insights into the differential mesotrypsin affinities of BPTI $\mathrm{P}_{2}{ }^{\prime}$ variants come from superposing the structures onto the previously reported structure of mesotrypsin bound to benzamidine $(1 \mathrm{H} 4 \mathrm{~W})$ [13]. Benzamidine is a small molecule that fills only the trypsin specificity pocket occupied by the $\mathrm{P}_{1} \mathrm{Arg}$ or Lys side chain of a substrate or polypeptide inhibitor; the mesotrypsin-benzamidine complex is expected to closely approximate the free enzyme. The superpositions reveal that very little adjustment is required of the mesotrypsin active site in order to accommodate BPTI-K15R/R17G binding; thus, it appears that enzyme and inhibitor are preconfigured for optimal complementarity, and that their interaction resembles lock-and-key type molecular recognition (Fig. $3 A$ ). By contrast, conformational changes involving displacement of Arg-193 in order to avoid steric clash with $\mathrm{P}_{2}{ }^{\prime} \mathrm{Arg}$ or Asp residues are required for binding to BPTI-WT (Fig. 3B) or BPTI-K15R/R17D (Fig. 3C). The binding data, showing 250 - 400-fold weaker binding for BPTI variants substituting $\mathrm{P}_{2}{ }^{\prime}$ Asp or Arg for Gly (Table 3), suggest that the reorganization of the enzyme active site required to accommodate the conformational shift in Arg-193 confers an energetic penalty.

\section{BPTI-K15R/R17G inhibits cancer cell malignant growth and invasion}

Since mesotrypsin has been functionally implicated in cancer cell malignant growth and invasion [9-11], it may offer a target for cancer therapy. Although a clinically useful mesotrypsin inhibitor would likely require greater selectivity toward mesotrypsin than is possessed by BPTI-K15R/R17G, the high mesotrypsin affinity of this inhibitor $\left(K_{i}=5.9\right.$ $\mathrm{nM}$ ) may allow for its use in studies evaluating the impact of pharmacological inhibition on malignant cancer cell phenotypes conferred by mesotrypsin activity. We have previously shown that in the HMT3522 breast cancer progression cell series, upregulation of mesotrypsin contributes to loss of basal polarity and increased proliferation, and that suppression of PRSS3 expression in malignant HMT3522 T4-2 cells inhibited disorganized proliferation and restored basal polarity and acinar morphology in a physiologically relevant 3D culture model [10]. Using this model to evaluate the effect of BPTI-wt vs. BPTI-K15R/ $\mathrm{R} 17 \mathrm{G}$ on malignant growth, we found a concentration-dependent reduction in colony size with both inhibitors; notably, the BPTI-K15R/R17G mutant was at least 10-fold more potent, since colony growth in the presence of $100 \mathrm{nM}$ BPTI-K15R/R17G was similar to that observed in cultures treated with $1000 \mathrm{nM}$ BPTI-wt (Fig. 4).

PRSS3/mesotrypsin has also been found to promote pancreatic cancer cell proliferation and invasion [11]. Using Capan-1 pancreatic cancer cells, which express high levels of PRSS3/ mesotrypsin [11], we measured the impact of PRSS3 knockdown by RNA interference and of mesotrypsin inhibition by BPTI-K15R/R17G treatment on cellular invasion in Matrigel transwell invasion assays (Fig. 5). Transduction of Capan-1 cells with a lentiviral shRNA construct specifically targeting PRSS3 led to efficient suppression of PRSS3/mesotrypsin expression both at the transcript level (Fig. 5A) and at the protein level (Fig. 5B). In Matrigel transwell invasion assays, either PRSS3 knockdown or treatment with $100 \mathrm{nM}$ BPTI-K15R/R17G led to equivalent inhibition of invasion by $70-75 \%$ relative to control cells (Fig. 5C). In aggregate, these results confirm that BPTI-K15R/R17G inhibits malignant growth and invasion in cancer models in which PRSS3/mesotrypsin has been found to play a role in promoting these hallmarks of cancer.

\section{DISCUSSION}

In the present study, we have used site-directed mutagenesis of the mesotrypsin substrate APPI and inhibitor BPTI to dissect specificity at the key $S_{2}{ }^{\prime}$ subsite, finding that bulky and charged residues strongly disfavor binding, while acidic residues facilitate catalysis. We have solved crystal structures to determine the structural underpinnings of these findings, and we have used the results to identify the mesotrypsin inhibitor BPTI-K15R/R17G, which 
is greatly improved in both mesotrypsin affinity and proteolytic stability. Because mesotrypsin is an enzyme that can contribute to tumor progression, we have tested BPTI$\mathrm{K} 15 \mathrm{R} / \mathrm{R} 17 \mathrm{G}$ in assays of breast cancer cell malignant growth and pancreatic cancer cell invasion, and have found significant anticancer activity.

The broad range of equilibrium association constants for APPI variants with dissimilar $\mathrm{P}_{2}{ }^{\prime}$ residues suggests that specificity at the $\mathrm{S}_{2}{ }^{\prime}$ subsite is likely to play a major role in shaping mesotrypsin substrate discrimination in vivo, creating specificity distinct from that of the less selective trypsins. The best mesotrypsin substrates as evaluated by specificity constants $k_{\text {cat }} / K_{m}$ possessed Gly or Ala at $\mathrm{P}_{2}{ }^{\prime}$, with specificity dominated by strong binding interactions, or alternatively possessed Asp or Glu at $\mathrm{P}_{2}{ }^{\prime}$, with specificity driven by rapid catalytic rates. These results contrast with previous studies of other trypsins: bovine trypsin displays little specificity at the $\mathrm{P}_{2}{ }^{\prime}$ position but strongly disfavors binding and cleavage of a substrate possessing $\mathrm{P}_{2}^{\prime}$ Asp [34], while rat anionic trypsin shows limited specificity favoring $\mathrm{P}_{2}{ }^{\prime}$ hydrophobic residues [35]. The mesotrypsin $\mathrm{P}_{2}{ }^{\prime}$ specificity defined through studies with the substrate APPI was recapitulated in studies with the inhibitor BPTI, where Gly at $\mathrm{P}_{2}{ }^{\prime}$ maximized inhibitor affinity, while Asp at $\mathrm{P}_{2}{ }^{\prime}$ seriously compromised inhibitor resistance to mesotrypsin proteolysis. The crystal structure of mesotrypsin in complex with BPTI-K15R/R17G suggests that a major factor contributing to improved affinity and complex stability is the precise steric complementarity of the $\mathrm{P}_{2}{ }^{\prime}$ Gly variant to the preexisting conformation of the mesotrypsin active site (Figs. 2A, 3A).

It is less obvious why acidic $\mathrm{P}_{2}{ }^{\prime}$ residues should enhance catalysis, but our crystal structure of the mesotrypsin.BPTI-K15R/R17D complex does offer several clues. The relatively weak electron densities for mesotrypsin Arg-193 and BPTI Asp-17 (Fig. 2F) are suggestive of conformational dynamics at the interface that may facilitate catalysis; our recent study comparing structures of mesotrypsin bound to BPTI vs. APPI also suggested that mobility at the primed side interface could be a major determinant of hydrolytic rates [18]. This factor may be particularly important for mesotrypsin cleavage within the constrained binding loops of canonical protease inhibitors like APPI and BPTI, which are typically highly resistant to cleavage by target proteases. Studies of BPTI variants by the Goldenberg laboratory [36, 37] and our previous studies with chymotrypsin inhibitor $2[38,39]$ have indicated that the ratedetermining step in proteolysis occurs after acyl-enzyme formation for some canonical inhibitors, when retention of the primed side amine leaving group in the active site blocks access to water and favors religation of the scissile peptide bond. Enhanced mobility of the primed side residues in the acyl-enzyme could accelerate dissociation of the amine leaving group, allowing access to water and progress of deacylation. The presence of an acidic residue at the $\mathrm{P}_{2}{ }^{\prime}$ position may further assist in chaperoning solvent into the active site, as we see evidence for multiple water peaks surrounding the Asp side chain carboxylate in our structure (Fig. 2F).

The stability and experimental tractability of the Kunitz domain has led to its exploration as a scaffold for development of protein therapeutics targeting serine proteases. BPTI, also known as aprotinin, was for decades used clinically under the trade name Trasylol as an antifibrinolytic agent [40], and a number of drugs based on human Kunitz scaffolds are under development targeting a variety of proteases [41-44]. Bikunin, a fragment of inter-atrypsin inhibitor comprised of two Kunitz domains, has been studied as an antimetastatic agent for treatment of ovarian carcinoma [41,45]; its anticancer activity is derived in part through inhibition of cell surface-associated plasmin [46]. The first Kunitz domain of tissue factor pathway inhibitor-1 (TFPI-1) has been engineered by phage display as a potent inhibitor of plasma kallikrein [47], for use in treatment of hereditary angiodema (HAE) [42]. Using a similar approach, the same scaffold has been optimized for plasmin specificity [48] and PEGylated for improved pharmacokinetics, for potential use as an antimetastatic agent 
[43]. The first Kunitz domain of hepatocyte growth factor activator inhibitor (HAI)-1 has also been recombinantly produced and PEGylated as an antimetastatic agent targeting hepsin, a transmembrane serine protease that promotes prostate cancer progression [44]. These studies lend support to the idea that a Kunitz-based inhibitor could theoretically be developed as a mesotrypsin-targeted therapeutic. However, while our prototype BPTIK15R/R17G offers impressive mesotrypsin affinity and stability, it offers little selectivity among trypsin isoforms, and may also inhibit other serine proteases featuring trypsin-like specificity. As $\mathrm{P}_{2}{ }^{\prime}$ engineering has had limited impact on affinity toward the major trypsins, future efforts to incorporate greater mesotrypsin selectivity will need to identify and exploit additional molecular determinants of binding specificity.

PRSS3 expression has been associated with cancer progression in several tumor types and model systems, suggesting that mesotrypsin may offer a target for cancer therapy. We have found that PRSS3 expression is upregulated with advancing malignancy in the HMT-3522 breast cancer progression series, where it promotes loss of cellular polarity in 3D culture and enhances proliferation [10]. Treatment with recombinant mesotrypsin stimulated malignant growth, while PRSS3 knockdown suppressed malignant growth [10]. In the present study, we find that treatment of HMT-3522 T4-2 cells with BPTI-K15R/R17G also suppresses malignant growth in this assay, and does so an order of magnitude more potently than BPTIWT (Fig. 4). It is perhaps surprising that biological potency was not enhanced to an even greater extent, given that mesotrypsin affinity was improved by more than three orders of magnitude in the mutant inhibitor. However, both BPTI and BPTI-K15R/R17G inhibit multiple trypsin isoforms (Table 5), and presumably other serine proteases of tryptic specificity. Since multiple serine proteases can contribute to malignancy, the net biological effects of these relatively nonspecific inhibitors represent a composite view of activity against a spectrum of proteases.

Ultimately, mesotrypsin inhibitors may be most likely to offer therapeutic benefit for cancers in which the enzyme contributes to metastasis, and for which existing therapies are of limited efficacy. In lung cancer patients, PRSS3 expression was associated with increased metastasis and poorer survival; in functional studies using NSCLC cells, overexpression of PRSS3 enhanced transendothelial migration, suggesting a mechanism by which mesotrypsin may stimulate metastasis [9]. As lung cancer is frequently diagnosed at advanced stages and has an overall five year survival rate of only $10-15 \%$ due primarily to metastasis [49], there is a need for better intervention strategies, one component of which might be the use of mesotrypsin inhibitors to suppress invasion. PRSS3/mesotrypsin expression has also been found to contribute to pancreatic cancer progression, correlating with metastasis and poor survival [11]. Mesotrypsin promoted pancreatic cancer cell proliferation and invasion in culture models, and stimulated tumor progression and metastasis in animal models [11]. Mesotrypsin may offer a promising therapeutic target in pancreatic cancer, a disease with a median survival of less than six months due to the aggressive metastasis of pancreatic cancers and their poor response to established chemotherapies [50]; this idea is supported by the efficacy of BPTI-K15R/R17G in suppressing the invasion of pancreatic cancer cells (Fig. 5). While further strategies to improve inhibitor selectivity are needed, our studies support the feasibility of protein engineering for development of mesotrypsin inhibitors, and highlight the potential for eventual therapeutic applications.

\section{Acknowledgments}

We thank Dr. Peter Storz and Heike Döppler for the gift of Capan-1 cells. We thank Dr. Nicole Murray and Amanda Butler for the suggestion of using SDF-1 as a chemoattractant in the pancreatic cancer cell invasion assays.

\section{FUNDING}


This research was supported by grants from the Bankhead-Coley Florida Biomedical Research Program [07BN-07], US Department of Defense [PC094054], and US National Cancer Institute [CA091956 (PI Don Tindall)] to ESR, and by grants from the US National Cancer Institute [CA122086; CA116201 (PI James Ingle)] and the Susan B. Komen Foundation [FAS0703855] to DCR. Diffraction data were measured at beamlines X12-B, X12-C, and X25 of the National Synchrotron Light Source, which is supported by the Offices of Biological and Environmental Research and of Basic Energy Sciences of the US Department of Energy, and the National Center for Research Resources of the National Institutes of Health.

\section{Abbreviations}

BPTI bovine pancreatic trypsin inhibitor

APPI amyloid precursor protein Kunitz protease inhibitor domain

Z-GPRpNA Carboxybenzyl-Gly-Pro-Arg-p-nitroanalide

$\beta M E$ 2-mercaptoethanol

TFA trifluoroacetic acid

DTT DL-dithiothreitol. Substrate residues surrounding the cleavage site are designated by the nomenclature of Schechter and Berger [1]: starting from the scissile bond, substrate residues are numbered $\mathrm{P}_{1}, \mathrm{P}_{2}, \mathrm{P}_{3}$, etc. in the direction of the $\mathrm{N}$-terminus (collectively the non-primed residues), and $\mathrm{P}_{1}{ }^{\prime}$, $\mathrm{P}_{2}{ }^{\prime}, \mathrm{P}_{3}{ }^{\prime}$, etc. in the direction of the C-terminus (collectively the primed residues). Corresponding enzyme subsites are numbered $\mathrm{S}_{1}, \mathrm{~S}_{2}, \mathrm{~S}_{3}$, etc.

\section{REFERENCES}

1. Schechter I, Berger A. On the size of the active site in proteases. I. Papain. Biochem. Biophys. Res. Commun. 1967; 27:157-162.

2. Kessenbrock K, Plaks V, Werb Z. Matrix metalloproteinases: regulators of the tumor microenvironment. Cell. 2010; 141:52-67. [PubMed: 20371345]

3. Turk B. Targeting proteases: successes, failures and future prospects. Nat. Rev. Drug Discov. 2006; 5:785-799. [PubMed: 16955069]

4. Cudic M, Fields GB. Extracellular proteases as targets for drug development. Curr. Protein Pept. Sci. 2009; 10:297-307. [PubMed: 19689354]

5. Lopez-Otin C, Matrisian LM. Emerging roles of proteases in tumour suppression. Nat. Rev. Cancer. 2007; 7:800-808. [PubMed: 17851543]

6. Rinderknecht H. Activation of pancreatic zymogens. Normal activation, premature intrapancreatic activation, protective mechanisms against inappropriate activation. Dig. Dis. Sci. 1986; 31:314-321. [PubMed: 2936587]

7. Wiegand U, Corbach S, Minn A, Kang J, Muller-Hill B. Cloning of the cDNA encoding human brain trypsinogen and characterization of its product. Gene. 1993; 136:167-175. [PubMed: 8294000]

8. Toth J, Siklodi E, Medveczky P, Gallatz K, Nemeth P, Szilagyi L, Graf L, Palkovits M. Regional distribution of human trypsinogen 4 in human brain at mRNA and protein level. Neurochem. Res. 2007; 32:1423-1433. [PubMed: 17406981]

9. Diederichs S, Bulk E, Steffen B, Ji P, Tickenbrock L, Lang K, Zanker KS, Metzger R, Schneider PM, Gerke V, Thomas M, Berdel WE, Serve H, Muller-Tidow C. S100 family members and trypsinogens are predictors of distant metastasis and survival in early-stage non-small cell lung cancer. Cancer Res. 2004; 64:5564-5569. [PubMed: 15313892]

10. Hockla A, Radisky DC, Radisky ES. Mesotrypsin promotes malignant growth of breast cancer cells through shedding of CD109. Breast Cancer Res. Treat. 2010; 124:27-38. [PubMed: 20035377] 
11. Jiang G, Cao F, Ren G, Gao D, Bhakta V, Zhang Y, Cao H, Dong Z, Zang W, Zhang S, Wong HH, Hiley C, Crnogorac-Jurcevic T, Lemoine NR, Wang Y. PRSS3 promotes tumour growth and metastasis of human pancreatic cancer. Gut. 2010; 59:1535-1544. [PubMed: 20947888]

12. Nyaruhucha CN, Kito M, Fukuoka SI. Identification and expression of the cDNA-encoding human mesotrypsin(ogen), an isoform of trypsin with inhibitor resistance. J. Biol. Chem. 1997; 272:10573-10578. [PubMed: 9099703]

13. Katona G, Berglund GI, Hajdu J, Graf L, Szilagyi L. Crystal structure reveals basis for the inhibitor resistance of human brain trypsin. J. Mol. Biol. 2002; 315:1209-1218. [PubMed: 11827488]

14. Szmola R, Kukor Z, Sahin-Toth M. Human mesotrypsin is a unique digestive protease specialized for the degradation of trypsin inhibitors. J. Biol. Chem. 2003; 278:48580-48589. [PubMed: 14507909]

15. Szepessy E, Sahin-Toth M. Human mesotrypsin exhibits restricted S1' subsite specificity with a strong preference for small polar side chains. Febs J. 2006; 273:2942-2954. [PubMed: 16759229]

16. Salameh MA, Soares AS, Hockla A, Radisky ES. Structural basis for accelerated cleavage of bovine pancreatic trypsin inhibitor (BPTI) by human mesotrypsin. J. Biol. Chem. 2008; 283:41154123. [PubMed: 18077447]

17. Salameh MA, Robinson JL, Navaneetham D, Sinha D, Madden BJ, Walsh PN, Radisky ES. The amyloid precursor protein/protease nexin 2 Kunitz inhibitor domain is a highly specific substrate of mesotrypsin. J. Biol. Chem. 2010; 285:1939-1949. [PubMed: 19920152]

18. Salameh MA, Soares AS, Navaneetham D, Sinha D, Walsh PN, Radisky ES. Determinants of affinity and proteolytic stability in interactions of Kunitz family protease inhibitors with mesotrypsin. J. Biol. Chem. 2010; 285:36884-36896. [PubMed: 20861008]

19. Rinderknecht H, Renner IG, Abramson SB, Carmack C. Mesotrypsin: a new inhibitor-resistant protease from a zymogen in human pancreatic tissue and fluid. Gastroenterology. 1984; 86:681692. [PubMed: 6698368]

20. Sahin-Toth M. Human cationic trypsinogen. Role of Asn-21 in zymogen activation and implications in hereditary pancreatitis. J. Biol. Chem. 2000; 275:22750-22755. [PubMed: 10801865]

21. Kukor Z, Toth M, Sahin-Toth M. Human anionic trypsinogen: properties of autocatalytic activation and degradation and implications in pancreatic diseases. Eur. J. Biochem. 2003; 270:2047-2058. [PubMed: 12709065]

22. Navaneetham D, Jin L, Pandey P, Strickler JE, Babine RE, Abdel-Meguid SS, Walsh PN. Structural and mutational analyses of the molecular interactions between the catalytic domain of factor XIa and the Kunitz protease inhibitor domain of protease nexin 2. J. Biol. Chem. 2005; 280:36165-36175. [PubMed: 16085935]

23. Navaneetham D, Sinha D, Walsh PN. Mechanisms and specificity of factor XIa and trypsin inhibition by protease nexin 2 and basic pancreatic trypsin inhibitor. J. Biochem. 2010; 148:467479. [PubMed: 20647553]

24. Otwinowski, Z.; Minor, W. Processing of X-ray Diffraction Data Collected in Oscillation Mode. In: Carter, CW., Jr; Sweet, RM., editors. Macromolecular Crystallography, part A. New York: Academic Press; 1997. p. 307-326.

25. McCoy AJ, Grosse-Kunstleve RW, Storoni LC, Read RJ. Likelihood-enhanced fast translation functions. Acta Crystallogr. D Biol. Crystallogr. 2005; 61:458-464. [PubMed: 15805601]

26. Adams PD, Grosse-Kunstleve RW, Hung LW, Ioerger TR, McCoy AJ, Moriarty NW, Read RJ, Sacchettini JC, Sauter NK, Terwilliger TC. PHENIX: building new software for automated crystallographic structure determination. Acta Crystallogr. D Biol. Crystallogr. 2002; 58:19481954. [PubMed: 12393927]

27. Emsley P, Cowtan K. Coot: model-building tools for molecular graphics. Acta Crystallogr. D Biol. Crystallogr. 2004; 60:2126-2132. [PubMed: 15572765]

28. Afonine PV, Grosse-Kunstleve RW, Adams PD. The Phenix refinement framework. CCP4 Newsletter. 2005; 42

29. Lee GY, Kenny PA, Lee EH, Bissell MJ. Three-dimensional culture models of normal and malignant breast epithelial cells. Nat. Methods. 2007; 4:359-365. [PubMed: 17396127] 
30. Cornish-Bowden, A. Fundamentals of enzyme kinetics. London: Portland Press; 1995.

31. Bigler TL, Lu W, Park SJ, Tashiro M, Wieczorek M, Wynn R, Laskowski M Jr. Binding of amino acid side chains to preformed cavities: interaction of serine proteinases with turkey ovomucoid third domains with coded and noncoded P1 residues. Protein Sci. 1993; 2:786-799. [PubMed: 8495199]

32. Lu W, Apostol I, Qasim MA, Warne N, Wynn R, Zhang WL, Anderson S, Chiang YW, Ogin E, Rothberg I, Ryan K, Laskowski M Jr. Binding of amino acid side-chains to S1 cavities of serine proteinases. J. Mol. Biol. 1997; 266:441-461. [PubMed: 9047374]

33. Krissinel E, Henrick K. Inference of macromolecular assemblies from crystalline state. J. Mol. Biol. 2007; 372:774-797. [PubMed: 17681537]

34. Coombs GS, Dang AT, Madison EL, Corey DR. Distinct mechanisms contribute to stringent substrate specificity of tissue-type plasminogen activator. J. Biol. Chem. 1996; 271:4461-4467. [PubMed: 8626799]

35. Schellenberger V, Turck CW, Rutter WJ. Role of the S' subsites in serine protease catalysis. Active-site mapping of rat chymotrypsin, rat trypsin, alpha-lytic protease, and cercarial protease from Schistosoma mansoni. Biochemistry. 1994; 33:4251-4257. [PubMed: 8155642]

36. Zakharova E, Horvath MP, Goldenberg DP. Functional and structural roles of the Cys14-Cys38 disulfide of bovine pancreatic trypsin inhibitor. J. Mol. Biol. 2008; 382:998-1013. [PubMed: 18692070]

37. Zakharova E, Horvath MP, Goldenberg DP. Structure of a serine protease poised to resynthesize a peptide bond. Proc. Natl. Acad. Sci. U.S.A. 2009; 106:11034-11039. [PubMed: 19549826]

38. Radisky ES, Koshland DE Jr. A clogged gutter mechanism for protease inhibitors. Proc. Natl. Acad. Sci. U.S.A. 2002; 99:10316-10321. [PubMed: 12142461]

39. Radisky ES, Kwan G, Lu CJ, Koshland DE Jr. Binding, proteolytic, and crystallographic analyses of mutations at the protease-inhibitor interface of the subtilisin BPN'/chymotrypsin inhibitor 2 complex. Biochemistry. 2004; 43:13648-13656. [PubMed: 15504027]

40. Fritz H, Wunderer G. Biochemistry and applications of aprotinin, the kallikrein inhibitor from bovine organs. Arzneimittelforschung. 1983; 33:479-494. [PubMed: 6191764]

41. Kobayashi H, Yagyu T, Inagaki K, Kondo T, Suzuki M, Kanayama N, Terao T. Therapeutic efficacy of once-daily oral administration of a Kunitz-type protease inhibitor, bikunin, in a mouse model and in human cancer. Cancer. 2004; 100:869-877. [PubMed: 14770446]

42. Williams A, Baird LG. DX-88 and HAE: a developmental perspective. Transfus. Apher. Sci. 2003; 29:255-258. [PubMed: 14572818]

43. Devy L, Rabbani SA, Stochl M, Ruskowski M, Mackie I, Naa L, Toews M, van Gool R, Chen J, Ley A, Ladner RC, Dransfield DT, Henderikx P. PEGylated DX-1000: pharmacokinetics and antineoplastic activity of a specific plasmin inhibitor. Neoplasia. 2007; 9:927-937. [PubMed: 18030361]

44. Li W, Wang BE, Moran P, Lipari T, Ganesan R, Corpuz R, Ludlam MJ, Gogineni A, Koeppen H, Bunting S, Gao WQ, Kirchhofer D. Pegylated kunitz domain inhibitor suppresses hepsin-mediated invasive tumor growth and metastasis. Cancer Res. 2009; 69:8395-8402. [PubMed: 19843851]

45. Kobayashi H, Yagyu T, Inagaki K, Kondo T, Suzuki M, Kanayama N, Terao T. Bikunin plus paclitaxel markedly reduces tumor burden and ascites in mouse model of ovarian cancer. Int. J. Cancer. 2004; 110:134-139. [PubMed: 15054878]

46. Kobayashi H, Shinohara H, Takeuchi K, Itoh M, Fujie M, Saitoh M, Terao T. Inhibition of the soluble and the tumor cell receptor-bound plasmin by urinary trypsin inhibitor and subsequent effects on tumor cell invasion and metastasis. Cancer Res. 1994; 54:844-849. [PubMed: 8306348]

47. Markland W, Ley AC, Ladner RC. Iterative optimization of high-affinity protease inhibitors using phage display. 2. Plasma kallikrein and thrombin. Biochemistry. 1996; 35:8058-8067. [PubMed: 8672510]

48. Markland W, Ley AC, Lee SW, Ladner RC. Iterative optimization of high-affinity proteases inhibitors using phage display. 1. Plasmin. Biochemistry. 1996; 35:8045-8057. [PubMed: 8672509] 
49. Wang T, Nelson RA, Bogardus A, Grannis FW Jr. Five-year lung cancer survival: which advanced stage nonsmall cell lung cancer patients attain long-term survival? Cancer. 2010; 116:1518-1525. [PubMed: 20108308]

50. Li D, Xie K, Wolff R, Abbruzzese JL. Pancreatic cancer. Lancet. 2004; 363:1049-1057. [PubMed: 15051286] 

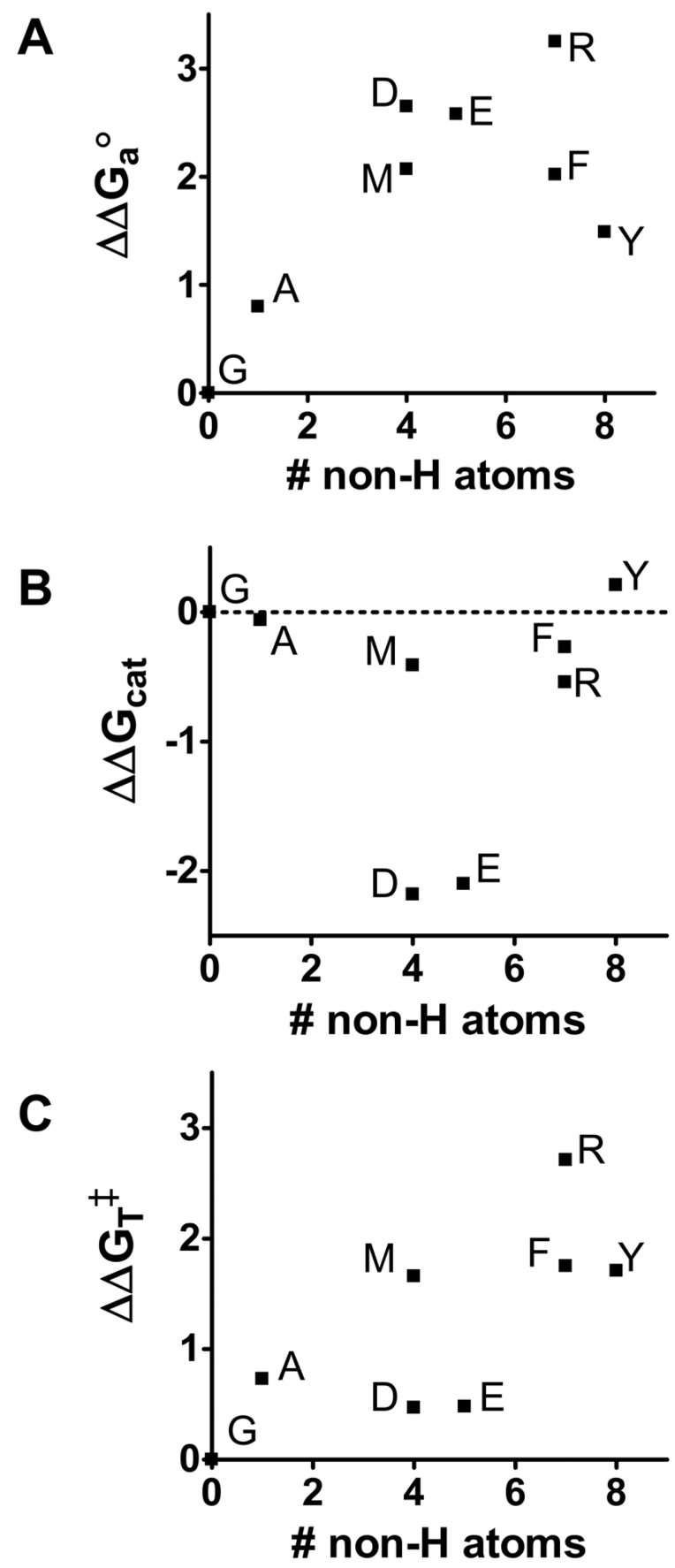

FIGURE 1. Impact of ${P_{2}}^{\prime}$ side chain size on free energies of association, catalysis, and transition state stabilization for mesotrypsin interaction with APPI

The number of non-hydrogen atoms in the $\mathrm{P}_{2}{ }^{\prime}$ side chain is plotted $v s$. the change in free energy of association relative to $\mathrm{P}_{2}^{\prime}$ Gly $\Delta \Delta G_{\mathrm{a}}{ }^{\circ}(\mathrm{Gly} 17 \mathrm{X})(\mathrm{A})$, the change in free energy of catalysis catalysis $\Delta \Delta G_{\text {cat }}($ Gly $17 \mathrm{X})(\mathrm{B})$, and the change in the transition-state stabilization energy $\Delta \Delta G_{\mathrm{T}}^{\ddagger}(\mathrm{Gly} 17 \mathrm{X})(\mathbf{C}) ; \mathrm{P}_{2}^{\prime}$ residues associated with each data point are indicated using the one-letter code. 

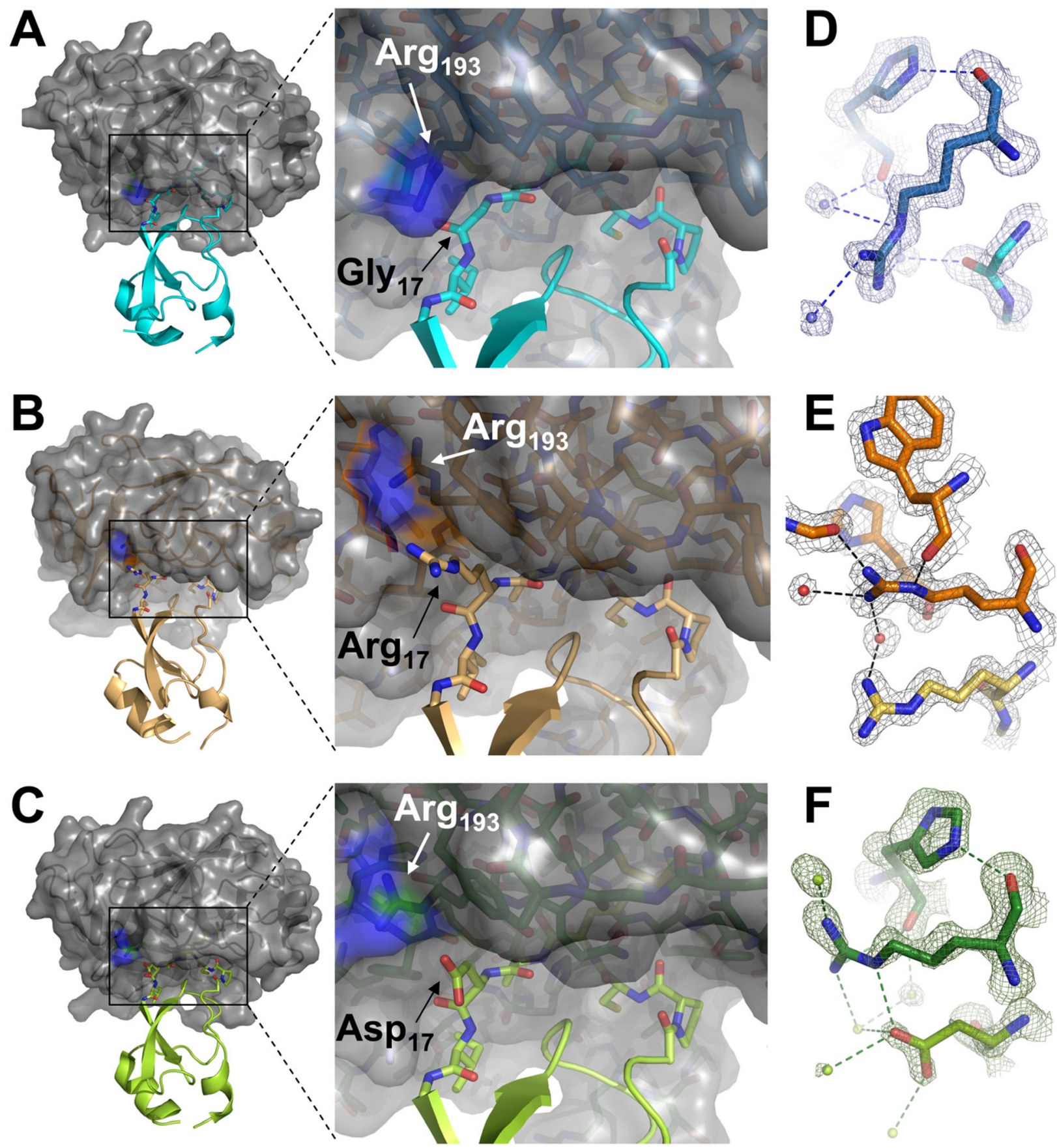

FIGURE 2. Distinct conformations of mesotrypsin Arg-193 shaped by alternative $P_{2}{ }^{\prime}$ residues of bound BPTI

Crystal structures of mesotrypsin in complex with BPTI-K15R/R17G (A), BPTI-WT (B), and BPTI-K15R/R17D (C) show globally similar complexes (left panels) with significant differences in interface topology in the vicinity of Arg-193 (surface shown in color). (A) In the BPTI-K15R/R17G complex, Arg-193 extends downward, enveloping BPTI Gly-17. In the BPTI-WT complex, Arg-193 recedes into a crevice on the surface of the enzyme (B), while a distinct intermediate conformation of Arg-193 is found in the BPTI-K15R/R17D complex (C). 2Fo-Fc density maps (contoured at 1.5 sigma) reveal well-ordered side chains for Arg-193 in the BPTI-K15R/R17G complex (D) and for both Arg-193 and the $\mathrm{P}_{2}{ }^{\prime}$ Arg in 
the BPTI-WT complex (E); Arg-193 and the $\mathrm{P}_{2}{ }^{\prime}$ Asp side chain are less well defined in the BPTI-K15R/R17D complex despite the higher resolution of this structure. 


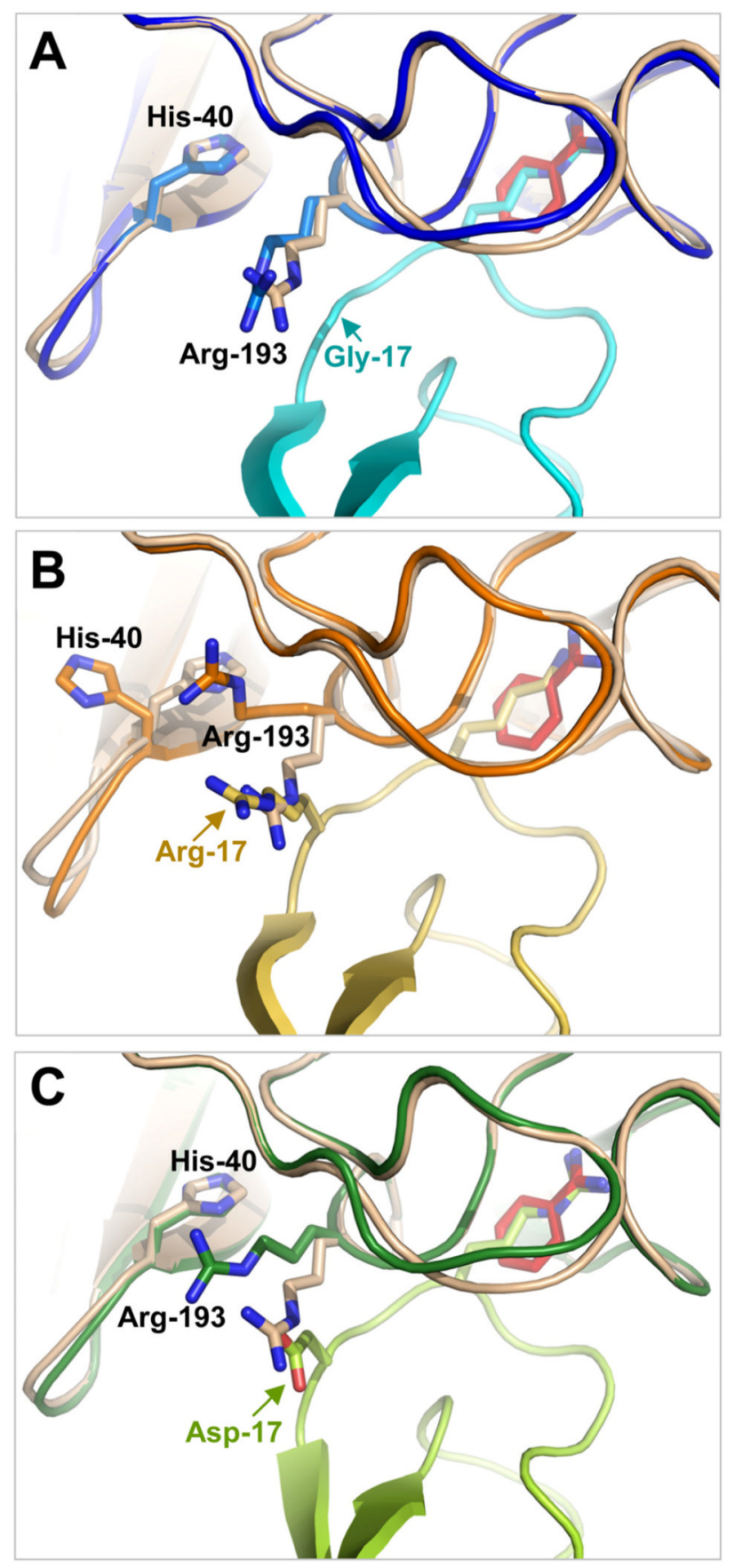

FIGURE 3. Conformational changes of mesotrypsin upon inhibitor binding

Superposition of mesotrypsin-BPTI structures with the mesotrypsin·benzamidine structure 1H4W (mesotrypsin beige, benzamidine red), in which the primed-side subsites are unfilled, reveals the conformational rearrangements required of mesotrypsin Arg-193 upon BPTI binding. Only minor adjustments of Arg-193 are observed in the mesotrypsin-BPTI-K15R/ R17G complex (A), whereas Arg-193 is shifted upward by $\sim 6 \AA$ in the mesotrypsin·BPTIWT structure (B) and by $\sim 3.5 \AA$ in the mesotrypsin-BPTI-K15R/R17D structure (C). 

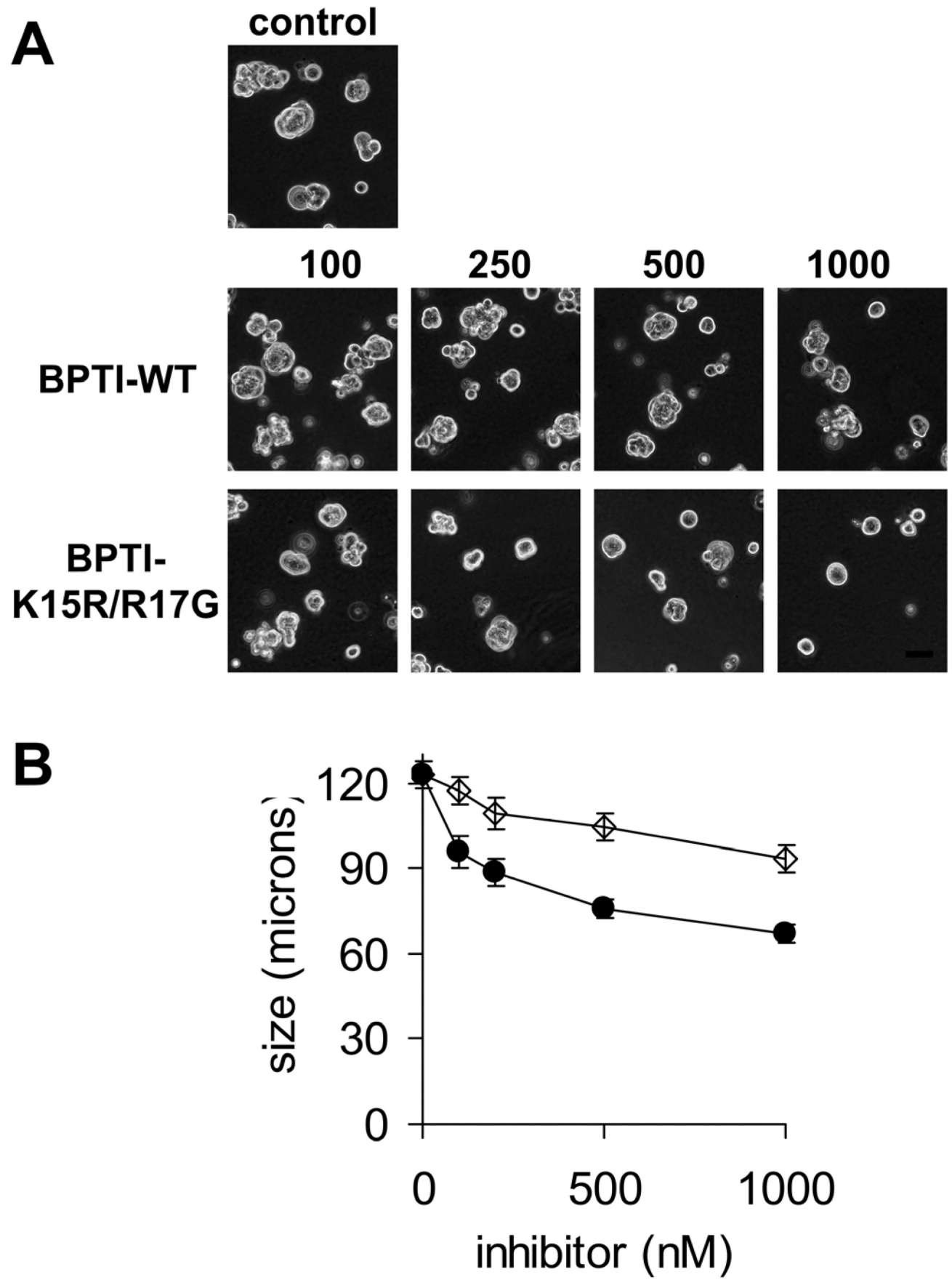

FIGURE 4. Effect of BPTI-K15R/R17G on malignant growth of T4-2 breast cancer cells in 3D culture

Cells treated with 100 - 1000 nM BPTI-WT, BPTI-K15R/R17G, or with buffer only (control) were grown in Matrigel for 7 days, then photographed and assessed for colony size. (A) Inhibitor concentration-dependent reduction in colony size relative to control cultures is more pronounced for the BPTI-K15R/R17G variant. Scale bar, $100 \mu \mathrm{M}$. (B) Quantification of colony size revealed significant inhibition of colony growth with BPTIWT treatment (open diamonds) at $500 \mathrm{nM}(\mathrm{p}<0.001$, unpaired $t$ test) and $1000 \mathrm{nM}$ concentration ( $\mathrm{p}<0.0001$, unpaired $t$ test), and highly significant growth inhibition with BPTI-K15R/R17G treatment (filled circles) at all concentrations tested ( $<<0.0001$, unpaired 
$t$ test), relative to control cells. Data are represented as mean \pm SEM for morphometry of 30 colonies per condition. 

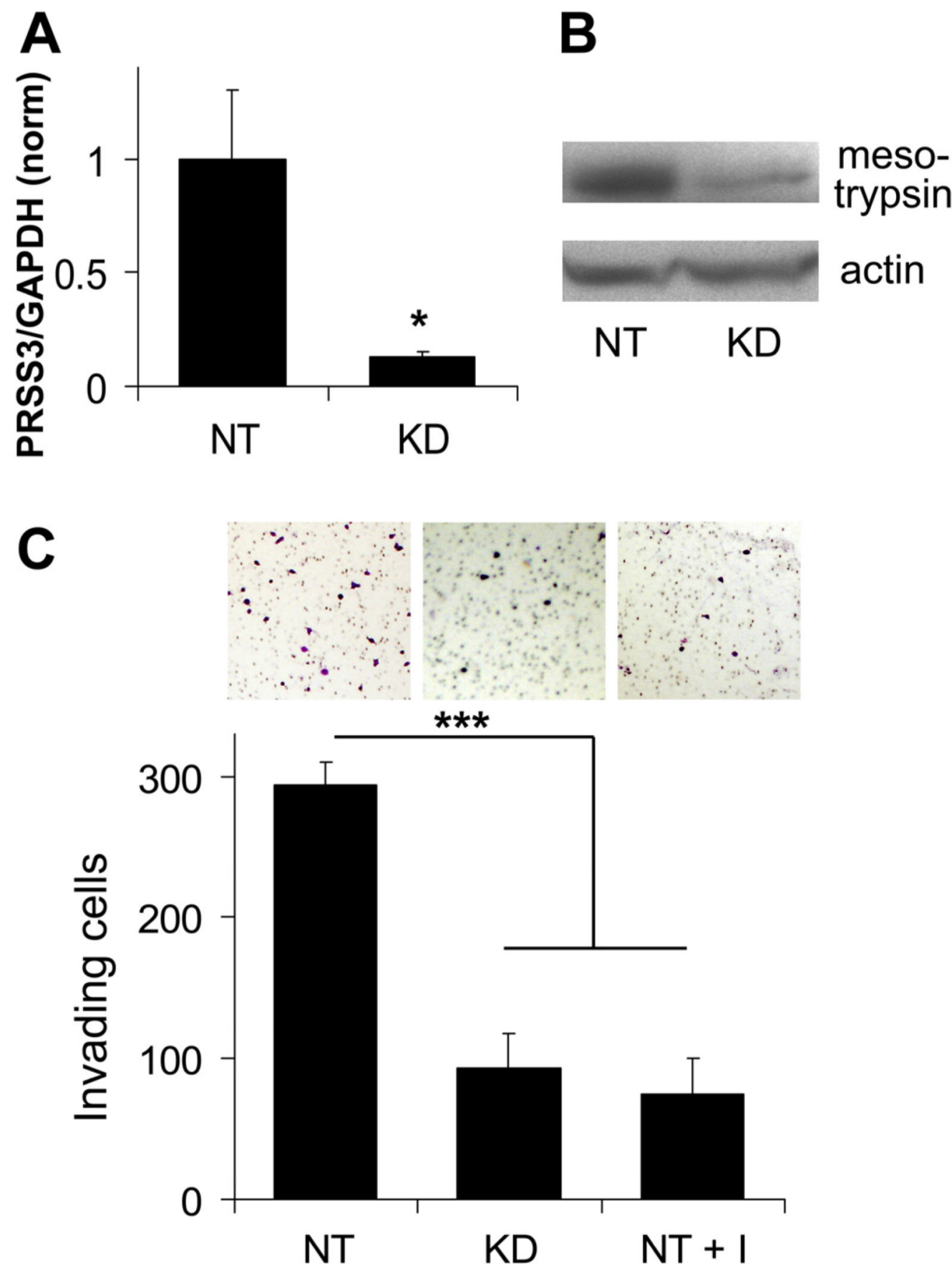

FIGURE 5. Effect of BPTI-K15R/R17G on invasion of pancreatic cancer cells

Transduction of Capan-1 cells with an shRNA construct specifically targeting PRSS3 resulted in suppression of expression at the transcript level as assessed by qRT/PCR (A), and at the protein level as assessed by Western blot (B). (C) In Matrigel transwell invasion assays, Capan-1 cells assayed in the presence of $100 \mathrm{nM} \mathrm{BPTI-K15R/R17G} \mathrm{(NT} \mathrm{+} \mathrm{I)}$ showed reduced invasion relative to control cells (NT); $100 \mathrm{nM}$ inhibitor gave results similar to shRNA knockdown of PRSS3 (KD). Graph shows mean and SEM for quadruplicate membranes; representative fields from invasion filters are shown above graphical results. *, $\mathrm{p}<0.05 ; * * *, \mathrm{p}<0.0005$ (unpaired $t$ test) 


\section{Table 1}

Strength of association of mesotrypsin with APPI variants

\begin{tabular}{|c|c|c|c|c|}
\hline Inhibitor & $\mathbf{P}_{\mathbf{2}}^{\prime}$ & $\begin{array}{c}K_{i} \pm \mathrm{SD} \\
(\mathbf{M})\end{array}$ & $\begin{array}{c}\text { Relative } K_{i} \\
\text { (fold diff) }\end{array}$ & $\underset{(\mathrm{kcal} / \mathrm{mol})}{\Delta \Delta \mathbf{G}_{\mathrm{a}}{ }^{\circ}(\mathrm{Gly} 17 \mathrm{X})}$ \\
\hline APPI-M17G & G & $4.71 \pm 0.13 \times 10^{-9}$ & 1.0 & 0.00 \\
\hline APPI-M17A & A & $1.71 \pm 0.27 \times 10^{-8}$ & 3.6 & 0.80 \\
\hline APPI-WT * & M & $1.36 \pm 0.19 \times 10^{-7}$ & 28.9 & 2.07 \\
\hline APPI-M17F & F & $1.26 \pm 0.11 \times 10^{-7}$ & 26.8 & 2.02 \\
\hline APPI-M17Y & $\mathrm{Y}$ & $5.33 \pm 0.32 \times 10^{-8}$ & 11.3 & 1.49 \\
\hline APPI-M17R ${ }^{* * *}$ & $\mathrm{R}$ & $9.20 \pm 0.99 \times 10^{-7}$ & 195.3 & 3.25 \\
\hline APPI-M17D & $\mathrm{D}$ & $3.46 \pm 0.18 \times 10^{-7}$ & 73.5 & 2.65 \\
\hline APPI-M17E & E & $3.09 \pm 0.18 \times 10^{-7}$ & 65.5 & 2.58 \\
\hline
\end{tabular}

Kinetic constants reported previously in [17].

K**inetic constants reported previously in [18]. 


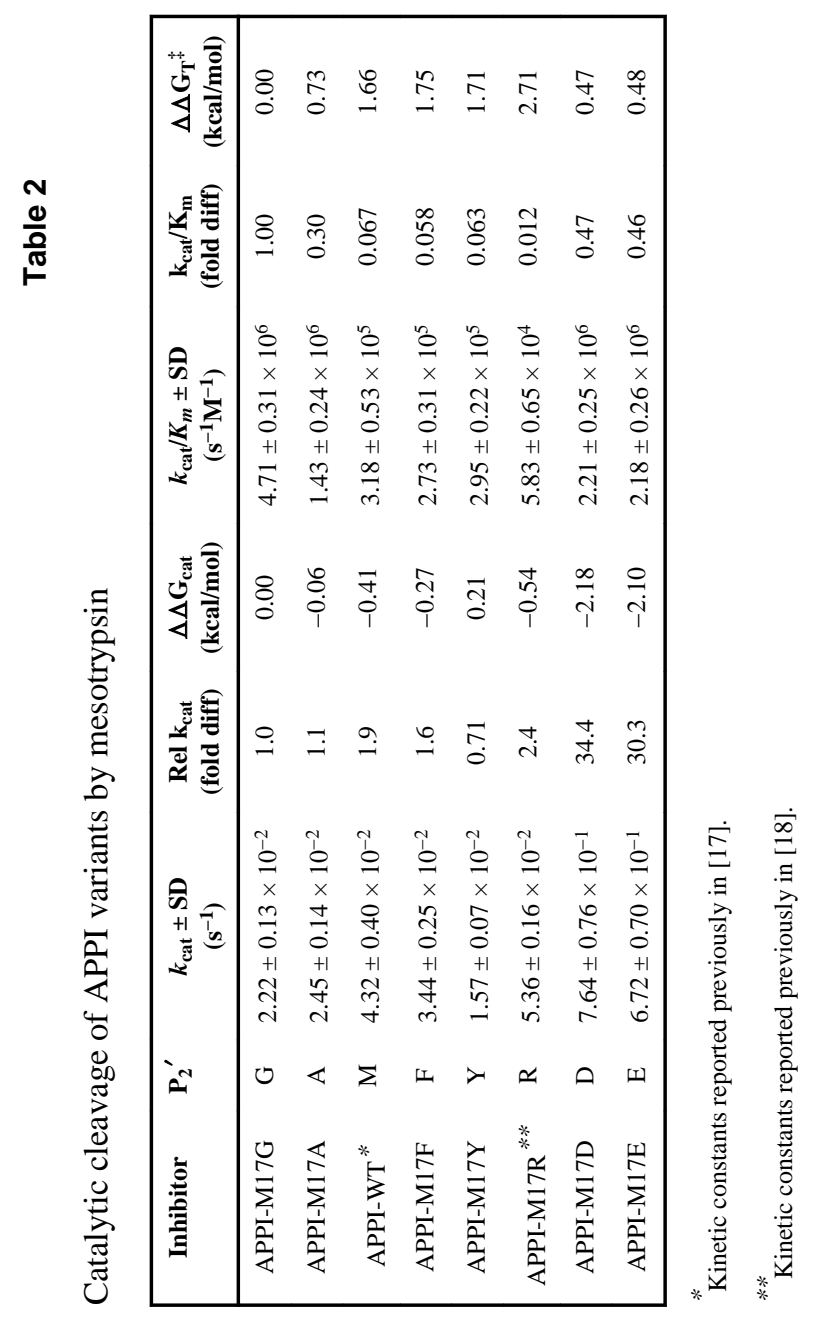


Table 3

Strength of association of mesotrypsin with BPTI variants

\begin{tabular}{|c|c|c|c|c|}
\hline Inhibitor & $\mathbf{P}_{2}^{\prime}$ & $\begin{array}{c}K_{i} \pm \mathrm{SD} \\
\quad(\mathrm{M})\end{array}$ & $\begin{array}{c}\text { Relative } K_{i} \\
\text { (fold diff) }\end{array}$ & $\underset{(\mathrm{kcal} / \mathrm{mol})}{\Delta \Delta \mathbf{G}_{\mathrm{a}}^{\circ}(\mathbf{G l y} 17 \mathbf{X})}$ \\
\hline BPTI-K15R/R17G & G & $5.9 \pm 1.7 \times 10^{-9}$ & 1.0 & 0.00 \\
\hline BPTI-K15R/R17M * & M & $2.18 \pm 0.01 \times 10^{-7}$ & 36.7 & 2.22 \\
\hline BPTI-K15R * & $\mathrm{R}$ & $2.38 \pm 0.20 \times 10^{-6}$ & 401.6 & 3.69 \\
\hline BPTI-K15R/R17D & $\mathrm{D}$ & $1.50 \pm 0.09 \times 10^{-6}$ & 252.4 & 3.41 \\
\hline
\end{tabular}

Kinetic constants reported previously in [18]. 
Table 5

Inhibition of human trypsin isoforms by BPTI and BPTI-K15R/R17G

\begin{tabular}{|c|c|c|c|}
\hline \multirow{2}{*}{ Trypsin isoform } & $\begin{array}{c}\text { BPTI-WT } \\
\boldsymbol{K}_{i} \pm \mathbf{S D}(\mathbf{M}) \\
(\boldsymbol{S I})^{*}\end{array}$ & $\begin{array}{c}\text { BPTI-K15R/R17G } \\
\boldsymbol{K}_{\boldsymbol{i}} \pm \mathbf{S D}(\mathbf{M}) \\
(\mathbf{S I})^{*}\end{array}$ & $\begin{array}{c}\text { fold } \\
\text { change }\end{array}$ \\
\hline \multirow{2}{*}{ Mesotrypsin } & $1.4 \pm 0.2 \times 10^{-5}$ & $5.9 \pm 1.7 \times 10^{-9}$ & 2277 \\
\cline { 2 - 4 } & $(1)$ & $(1)$ & \\
\hline \multirow{2}{*}{ Cationic trypsin } & $2.0 \pm 0.1 \times 10^{-11^{* *}}$ & $3.3 \pm 0.1 \times 10^{-11}$ & 0.61 \\
\cline { 2 - 4 } & $\left(1.5 \times 10^{-6}\right)$ & $\left(5.6 \times 10^{-3}\right)$ & \\
\hline \multirow{2}{*}{ Anionic trypsin } & $1.7 \pm 0.2 \times 10^{-11}$ & $3.0 \pm 0.3 \times 10^{-11}$ & 0.55 \\
\cline { 2 - 4 } & $\left(1.2 \times 10^{-6}\right)$ & $\left(5.1 \times 10^{-3}\right)$ & \\
\hline
\end{tabular}

Selectivity Index $(\mathrm{SI})=K_{i} / K_{i}($ mesotrypsin $)$

$K_{i}$ reported previously in [16]. 
Table 6

Data collection and refinement statistics for mesotrypsin/BPTIcomplexes

\begin{tabular}{|ccc|}
\hline & Mesotrypsin-BPTI-K15R/R17G & Mesotrypsin-BPTI-K15R/R17D \\
\hline PDB ID & $3 \mathrm{P} 92$ & $3 \mathrm{P} 95$ \\
Complexes per ASU & 1 & 1 \\
Space group & $\mathrm{P} 2_{1}$ & $\mathrm{P} 2_{1}$ \\
Unit cell, $\AA$ & $44.3,39.2,68.8$, & $43.9,39.1,68.5$, \\
& $90^{\circ}, 100.3^{\circ}, 90^{\circ}$ & $90^{\circ}, 100.1^{\circ}, 90^{\circ}$ \\
Resolution range, $\AA$ & $33.85-1.60$ & $33.82-1.30$ \\
Unique reflections & 27,579 & 53,441 \\
Completeness, $\%$ & $88.9\left(46.7^{*}\right)$ & $94.4\left(65.0^{* *}\right)$ \\
Multiplicity & $6.5(3.8)$ & $6.3(3.8)$ \\
I/S.D. & $39.8(18.4)$ & $17.1(6.5)$ \\
$R_{\text {sym }}$ & $0.032(0.081)$ & $0.068(0.227)$ \\
$R_{\text {cryst }} / R_{\text {free }}$ & $11.13 / 15.86$ & $11.05 / 13.19$ \\
R.m.s.d. bonds, $\AA$ & 0.007 & 0.016 \\
R.m.s.d. angles, ${ }^{\circ}$ & 0.907 & 1.335 \\
\hline
\end{tabular}

* Completeness at $1.85 \AA$ is $95.1 \%$

*** Completeness at $1.43 \AA$ is $97.1 \%$ 